\title{
Revista Bravo! (1997 - 2013): Percurso Teórico-Metodológico
}

\author{
Revista ;Bravo! (1997 - 2013): Recorrido Teórico-Metodológico \\ Bravo! Magazine (1997 - 2013): Theoretical-Methodological Walkthrough
}

\section{Lislaine Sirsi Cansi ${ }^{1}$}

\begin{abstract}
Resumo
A imprensa, utilizada como objeto e como fonte de pesquisa, têm oferecido novas possibilidades de análise no campo da História da Educação. Este artigo diz respeito ao percurso teórico-metodológico de uma pesquisa, a qual possui a imprensa periódica, especificamente a revista Bravo!, como objeto e como fonte de investigação. A revista Bravo! consiste em um impresso periódico mensal voltado à cultura. Pretende-se apresentar o objeto e, alicerçado nas fontes, realizar uma descrição analítica do processo de pesquisa. Nesse momento, estudos sobre o uso de periódicos como fonte documental e objeto de pesquisa serão considerados.
\end{abstract}

Palavras-Chave: imprensa periódica; percurso teórico-metodológico; revista Bravo!.

\section{Resumen}

La prensa, utilizada como objeto y como fuente de investigación, ha ofrecido nuevas posibilidades de análisis en el campo de la Historia de la Educación. Este artículo se refiere al recorrido teórico-metodológico de una investigación, la cual posee la prensa periódica, específicamente la revista Bravo!, como objeto y como fuente de investigación. La revista Bravo! consiste en un impreso periódico mensual volcado a la cultura. Se pretende presentar el objeto y, basándose en las fuentes, realizar una descripción analítica del proceso de investigación. En ese momento, se considerarán estudios sobre el uso de periódicos como fuente documental y objeto de investigación.

Palabras claves: prensa periódica; recorrido teórico-metodológico; revista Bravo!.

\begin{abstract}
The press, used as an object and as a source of research, have offered new possibilities of analysis in the field of History of Education. This article concerns the theoretical-methodological course of a research, which has the periodic press, specifically the Bravo! magazine, as an object and as a source of research. The Bravo! magazine consists of a monthly periodical printed for culture. It is intended to present the object and, based on the sources, to perform an analytical description of the research process. At that moment, studies on the use of periodicals as documentary source and object of research, will be considered.
\end{abstract}

Keywords: periodical press; theoretical-methodological Walkthrough; Bravo! magazine.

\section{Introdução}

A revista Bravo! consiste em um impresso periódico mensal voltado à cultura, particularmente ao universo da literatura e das artes. Neste artigo, considera-se como recorte temporal o período que diz respeito a sua primeira edição, entre outubro de 1997 e agosto de

\footnotetext{
${ }^{1}$ Doutoranda em Educação (PPGE/UFPel); Mestra em Artes Visuais (PPGAV/UFPel); Pelotas; Rio Grande do Sul; Brasil; lislaine_c@yahoo.com.br.
} 
2013. A revista iniciou sob gerência da Editora D'Avila e terminou sob o comando da Editora Abril. Em se tratando de uma revista publicada mensalmente por quase 16 anos no mercado editorial brasileiro, contém, para a pesquisa, um total de 192 exemplares, sem computar as edições especiais. É a partir desse montante que se pensou em certo percurso teóricometodológico. Nesse sentido, na primeira parte do texto, estudos sobre o uso de periódicos como fonte documental e objeto de pesquisa, serão considerados. Já, na segunda seção do texto, pretende-se apresentar o objeto e, alicerçado nas fontes, realizar uma descrição analítica do percurso teórico-metodológico objetivando a inserção da pesquisa no âmbito da História da Educação. Ressalta-se que as fontes a serem utilizadas serão as fontes textuais e iconográficas pertencentes ao editorial denominado “Artes Plásticas/Artes Visuais".

\section{Os impressos na História da Educação}

Em se tratando da área da História da Educação, dentre as várias possibilidades teórico-metodológicas, opta-se pela História Cultural como referência epistemológica, a qual se torna mais precisa e mais evidente nas décadas finais do século XX. Sobre ela, Burke (2008, p. 10) afirma que "o terreno comum dos historiadores culturais pode ser descrito como a preocupação com o simbólico e suas interpretações". Galvão e Lopes concordam com o autor ao assegurar que a maior contribuição da História Cultural ocorre quando o objeto de pesquisa for utilizado para

compreender como determinadas visões de mundo, - materializadas em produtos culturais - foram produzidas e disseminadas por diferentes grupos sociais. No centro desse debate está a tentativa de entender como (por meio de processos e em que condições) os sujeitos atribuem significado ao mundo em que vivem (GALVÃO; LOPES, 2010, p. 33).

Compreende-se, dessa maneira, a possibilidade de que o foco de investigações se amplie, se diversifique e se construa com base em objetos não necessariamente considerados legítimos pela tradição histórica. Barros (2013, p. 55) afirma que a riqueza da História Cultural está nas diversas possibilidades de objetos, a exemplo, a cultura popular, a cultura letrada, representações, práticas discursivas, instituições, mediação cultural através de intelectuais e "quaisquer outros campos temáticos perpassados pela noção abrangente de "cultura"”. Esses objetos são alocados entre os cinco eixos fundamentais da História Cultural, objetos culturais, sujeitos, práticas, processos e padrões (BARROS, 2013).

Sabe-se que as novas abordagens, os novos problemas e os novos objetos da História Cultural alargaram os estudos e as possibilidades de análise nas pesquisas da História da Educação (LE GOFF; NORA, 1974; 1995a; 1995b). Nesse contexto, insere-se a imprensa 
como objeto e como fonte de investigação, a qual tem sido mais recorrente no Brasil a partir da década de 1970. O desprezo às pesquisas científicas utilizando a imprensa, especificamente os jornais, como fonte, foi motivado pela compreensão de que o seu uso era instrumental e ingênuo, ao tomar os periódicos como "meros receptáculos de informações a serem selecionadas, extraídas e utilizadas ao bel prazer do pesquisador" (LUCA in PINSKY, 2005, p. 116). Desse modo, havia a compreensão de que somente os investigadores que não tinham fontes tomavam a imprensa como fonte de suas pesquisas, sendo ela por vezes utilizada de forma subordinada, apoiada em outro tipo de documento, como algo ressonante.

Na década de 1970, através de crítica rigorosa, buscou-se nos periódicos algo para além daquilo que se podia confirmar. Trata-se de possibilidades ensejadas pelos jornais, dados de natureza econômica ou demográfica e aspectos variados da sociedade brasileira. Autores pioneiros como Ana Maria de Almeida Camargo, Gilberto Freyre, Nelson Werneck Sodré se contrapuseram à ideia de "ingenuidade do pesquisador" ao tomar a imprensa como fonte primária de pesquisa (LUCA, 2005).

Entre os muitos autores que pesquisam sobre imprensa, é possível, nesse momento da pesquisa, citar Ana Luiza Martins e Tânia Regina de Luca (2013).; Denice Bárbara Catani e Maria Helena Câmara Bastos (2002); Analete Regina Schelbauer e José Carlos Souza Araújo. (2007); António Nóvoa (1997); Maria Helena Rolim Capelato (1988); Heloisa de Faria Cruz e Maria do Rosário da Cunha Peixoto (2007).

O historiador de cultura ao optar pelos impressos, revistas ou periódicos, expande as suas fontes de pesquisa para além das tradicionais e, de acordo com Chartier (1987), ao captar a história de determinado impresso, tem acesso a dispositivos discursivos concernentes à produção, à circulação e à apropriação dos leitores. Sobre isso, destaca-se que:

\footnotetext{
A análise desses materiais possibilita apreender como os indivíduos produzem seu mundo social e cultural - na intersecção das estratégias do impresso, que visa instaurar uma ordem desejada pela autoridade que o produziu ou permitiu sua publicação, com a apropriação feita pelos leitores: nesse espaço, percebemos as dependências que os unem e os conflitos que os separaram, detectamos suas alianças e enfrentamentos (VILELA ET AL. IN MENEZES, p. 402, 2004).
}

Entre as muitas pesquisas com investimentos na análise de impressos periódicos revistas, pode-se citar: Ana Luiza Martins (2001), Revista em revista: imprensa e práticas culturais em tempos de República, São Paulo (1890-1922), que conceituou esse gênero de impresso, esclareceu suas condições de produção, mapeou o seu processo de difusão e inquiriu acerca da natureza de semanários e mensários circulantes pela cidade de São Paulo; Maria Celeste Mira, em O leitor e a banca de jornal, sob o qual discute acerca do histórico da 
trajetória da revista no país, sobretudo na década de 60; Márcia Padilha, que discorre sobre o caráter multifacetado da cidade de São Paulo, através da publicidade contida nas páginas de Ariel e A Cigarra; Ana Maria Mauad, através de perspectiva histórico-semiótica das revistas Careta e Cruzeiro, analisa a representação social e os códigos de comportamento da classe dominante carioca na primeira metade do século XX (LUCA, 2005). As abordagens de Marize Carvalho Vilela (2000), em Discursos, cursos e recursos: autores da Revista Educação (1927-1961), Cláudia Panizzolo Batista da Silva (2001), em Atualizando pedagogias para o ensino médio: um estudo sobre a revista Atualidades Pedagógicas (19501962), e Luiz Carlos Barreira, em Escola, periodismo e vida urbana: educação popular e imprensa operária em São Paulo (1888-1925), são estudos relevantes para compreendermos como é possível analisar os impressos periódicos.

De acordo com Luca (2005), a lista de procedimentos teórico-metodológicos podem ser os seguintes:

\begin{abstract}
Encontrar as fontes e constituir uma longa e representativa série. Localizar a(s) publicação(ções) na história da imprensa. Atentar para as características de ordem material (periodicidade, impressão; papel, uso/ausência de iconografia e de publicidade). Assenhorar-se da forma de organização interna do conteúdo. Caracterizar o material iconográfico presente, atentando para as opções estéticas e funções cumpridas por ele na publicação. Caracterizar o grupo responsável pela publicação. Identificar os principais colaboradores. Identificar o público a que se destinava. Identificar as fontes de receita. Analisar todo o material de acordo com a problemática escolhida (LUCA, 2005, p. 142).
\end{abstract}

Partindo da lista de procedimentos de Luca, sabemos que, em se tratando de um impresso como objeto e fonte de pesquisa, há muitas possibilidades de investigação. Luca (2005) afirma que não há receita e que a pesquisa dependerá da fonte, portanto, a listagem anterior se caracteriza como procedimento inicial. A seguir, será apresentado o percurso teórico-metodológico sobre a revista Bravo!.

\title{
3. A investigação sobre a revista Bravo!
}

A revista Bravo! se caracteriza como um impresso periódico mensal brasileiro dedicado à cultura. Identificada como uma revista brasileira inteiramente dedicada a todas as artes, carregava consigo, a partir da edição no 128, o slogan "o melhor da cultura" no mês x do ano X. As reportagens apresentadas focavam o campo da literatura e de diversas dimensões do universo artístico, principalmente Artes Plásticas/ArtesVisuais, Teatro, Dança, Música e Cinema. Seu discurso abrangia a cultura de modo ensaístico-crítico.

Neste estudo, a delimitação temporal corresponde a sua primeira edição, aos anos de 1997 a 2013. Lançada em outubro de 1997, pela extinta editora D’Avila Comunicações Ltda, 
foi encerrada em agosto de 2013 pela Editora Abril. A sua segunda edição corresponde ao seu relançamento em agosto de 2016, por dois ex-executivos da editora Abril, os jornalistas Helena Bagnoli e Guilherme Werneck, sob licença da editora Abril. Desde então a revista foi publicada somente na versão online, mas em seguida, também passou a apresentar versões trimestrais impressas. Reitera-se que os números da segunda edição não serão inseridos na análise desse artigo.

A primeira etapa da investigação foi fazer a busca e a apreensão do objeto. Frente ao tempo de publicação da edição 1997 - 2013, foi encontrado o total de 192 exemplares, sendo as edições especiais não consideradas nessa amostragem.

O segundo momento foi perpassado pelo processo de catalogação, objetivando caracterizar objeto e fontes. O processo de catalogação foi longo. Inicialmente, duas tabelas foram construídas, uma considerando a capa como fonte, outra, seguindo o expediente da edição. A seguir, o quadro 1 e o quadro 2 explanam dados referentes aos quatro primeiros exemplares da edição 1997 - 2013.

Quadro 1 - Identificação do objeto (tema).

\begin{tabular}{|l|l|l|l|l|l|l|l|l|}
\hline Vol. & $\mathrm{N}^{\text {}}$ & Mês & Ano & Tema da capa & Subtítulo do tema da capa & Seção do tema & Proveniência & Editora \\
\hline 1 & 1 & Out & 1997 & $\begin{array}{l}\text { O gordo ano 50 do } \\
\text { Masp }\end{array}$ & $\begin{array}{l}\text { Entre Botero, Michelangelo, } \\
\text { Monet e Portinari, o museu da } \\
\text { elite se impõe como a casa do } \\
\text { povo }\end{array}$ & Artes Plásticas & BCS/UFPel & D'Avila \\
\hline 1 & 2 & Nov & 1997 & $\begin{array}{l}\text { No olho do } \\
\text { furacão }\end{array}$ & $\begin{array}{l}\text { Relato de um vendaval: } \\
\text { Caetano Veloso, o mais } \\
\text { querido produto cultural da } \\
\text { mídia, lança CD e livro }\end{array}$ & Música & CD ROM & D’Avila \\
\hline 1 & 3 & Dez & 1997 & $\begin{array}{l}\text { Absolutamente } \\
\text { moderna }\end{array}$ & $\begin{array}{l}\text { O poder subversivo da obra de } \\
\text { Clarice Lispector nunca esteve } \\
\text { tão à frente dos tempos, e sua } \\
\text { personalidade fascina o } \\
\text { mundo }\end{array}$ & Livros & CD ROM & D’Avila \\
\hline 1 & 4 & Jan & 1998 & $\begin{array}{l}\text { A face mais bonita } \\
\text { da violência: }\end{array}$ & $\begin{array}{l}\text { O cinema de José Henrique } \\
\text { Fonseca, Cláudia Abreu e } \\
\text { Patrícia Melo faz, à Tarantino, } \\
\text { a versão brasileira da estética } \\
\text { do sangue }\end{array}$ & Cinema & CD ROM & D'Avila \\
\hline
\end{tabular}

Fonte: elaborada pela autora tendo o objeto de estudo como base.

Quadro 2 - Identificação do objeto (técnica).

\begin{tabular}{|l|l|l|l|l|l|l|l|l|l|}
\hline$N^{\circ}$ & $\begin{array}{l}\text { Valor } \\
(\mathrm{R} \$)\end{array}$ & Pág. & Dimensão & $\begin{array}{l}\text { Presidente/ } \\
\text { editor }\end{array}$ & $\begin{array}{l}\text { Diretor(a) de } \\
\text { Redação/ } \\
\text { Redator(a)- } \\
\text { chefe }\end{array}$ & $\begin{array}{l}\text { Editores- } \\
\text { Chefes ou } \\
\text { Seniores }\end{array}$ & Editor(a) & $\begin{array}{l}\text { Diretor(a) } \\
\text { de Arte }\end{array}$ & $\begin{array}{l}\text { Diretor(a) } \\
\text { /editor(a) } \\
\text { de } \\
\text { fotografia }\end{array}$ \\
\hline
\end{tabular}


RELACult - Revista Latino-Americana de Estudos em Cultura e Sociedade

\begin{tabular}{|c|c|c|c|c|c|c|c|c|c|}
\hline 1 & 5 & 163 & $\begin{array}{l}23,3 \mathrm{x} \\
30 \mathrm{~cm}\end{array}$ & $\begin{array}{l}\text { Luiz Felipe } \\
\text { D'Avila }\end{array}$ & $\begin{array}{l}\text { Wagner } \\
\text { Carelli }\end{array}$ & $\begin{array}{l}\text { Vera de } \\
\text { Sá }\end{array}$ & $\begin{array}{l}\text { André Luiz } \\
\text { Barros; Luis } \\
\text { S. Krausz, } \\
\text { Regina } \\
\text { Porto }\end{array}$ & $\begin{array}{l}\text { Noris } \\
\text { Lima }\end{array}$ & $\begin{array}{l}\text { Eduardo } \\
\text { Simões }\end{array}$ \\
\hline 2 & 5 & 163 & $\begin{array}{l}23,3 \mathrm{x} \\
30 \mathrm{~cm}\end{array}$ & $\begin{array}{l}\text { Luiz Felipe } \\
\text { D'Avila }\end{array}$ & $\begin{array}{l}\text { Wagner } \\
\text { Carelli }\end{array}$ & $\begin{array}{l}\text { Vera de } \\
\text { Sá }\end{array}$ & $\begin{array}{l}\text { André Luiz } \\
\text { Barros; Luis } \\
\text { S. Krausz, } \\
\text { Regina } \\
\text { Porto }\end{array}$ & $\begin{array}{l}\text { Noris } \\
\text { Lima }\end{array}$ & $\begin{array}{l}\text { Eduardo } \\
\text { Simões }\end{array}$ \\
\hline 3 & 5 & 163 & $\begin{array}{l}23,3 \mathrm{x} \\
30 \mathrm{~cm}\end{array}$ & $\begin{array}{l}\text { Luiz Felipe } \\
\text { D'Avila }\end{array}$ & $\begin{array}{l}\text { Wagner } \\
\text { Carelli }\end{array}$ & $\begin{array}{l}\text { Reinaldo } \\
\text { Azevedo; } \\
\text { Vera de } \\
\text { Sá }\end{array}$ & $\begin{array}{l}\text { Josiane } \\
\text { Lopes, } \\
\text { André Luiz } \\
\text { Barros; } \\
\text { Michel } \\
\text { Laub, } \\
\text { Regina } \\
\text { Porto }\end{array}$ & $\begin{array}{l}\text { Noris } \\
\text { Lima }\end{array}$ & $\begin{array}{l}\text { Eduardo } \\
\text { Simões }\end{array}$ \\
\hline 4 & 5 & 147 & $\begin{array}{l}23,3 \mathrm{x} \\
30 \mathrm{~cm}\end{array}$ & $\begin{array}{l}\text { Luiz Felipe } \\
\text { D’Avila }\end{array}$ & $\begin{array}{l}\text { Wagner } \\
\text { Carelli }\end{array}$ & $\begin{array}{l}\text { Reinaldo } \\
\text { Azevedo; } \\
\text { Vera de } \\
\text { Sá }\end{array}$ & $\begin{array}{l}\text { Josiane } \\
\text { Lopes, } \\
\text { André Luiz } \\
\text { Barros; } \\
\text { Michel } \\
\text { Laub, } \\
\text { Regina } \\
\text { Porto }\end{array}$ & $\begin{array}{l}\text { Noris } \\
\text { Lima }\end{array}$ & $\begin{array}{l}\text { Eduardo } \\
\text { Simões }\end{array}$ \\
\hline
\end{tabular}

Fonte: elaborada pela autora tendo o objeto de estudo como base.

O quadro 1 remete aos dados de identificação geral de cada periódico, contendo informações como volume, número, mês e ano de publicação, chamada principal da capa (dividida em principal e secundária de acordo com a hierarquia tipográfica, em ordem decrescente de tamanho), editorial ao qual se refere à chamada principal da capa, proveniência e editora. O quadro 2 concerne aos dados de identificação técnica de cada periódico, contendo informações como volume, número, valor da revista, quantidade de páginas, dimensão, editora, presidente/editor, diretor(a) de redação/redator(a)-chefe, editor-chefe/ editor-sênior, editor, diretor(a) ou editor(a) de arte, diretor(a) ou editor(a) de fotografia. Algumas informações dos quadros foram acrescentadas durante o processo de catalogação, em função das mudanças que ocorreram ao longo da edição 1997 - 2013. Tais quadros permitiram conhecer a revista de uma forma geral.

Durante a construção dos quadros anteriormente citados e, objetivando catalogar aspectos referentes à materialidade, foi construído um arquivo contendo as imagens de todas as capas da edição estudada (Figura 1). 

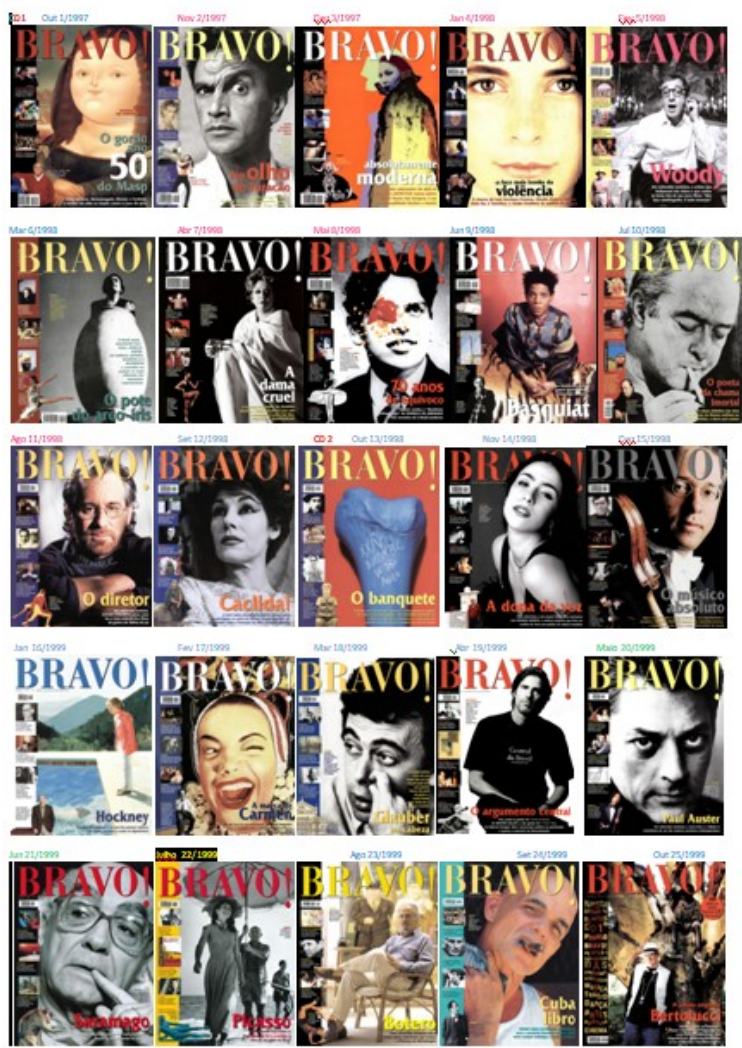
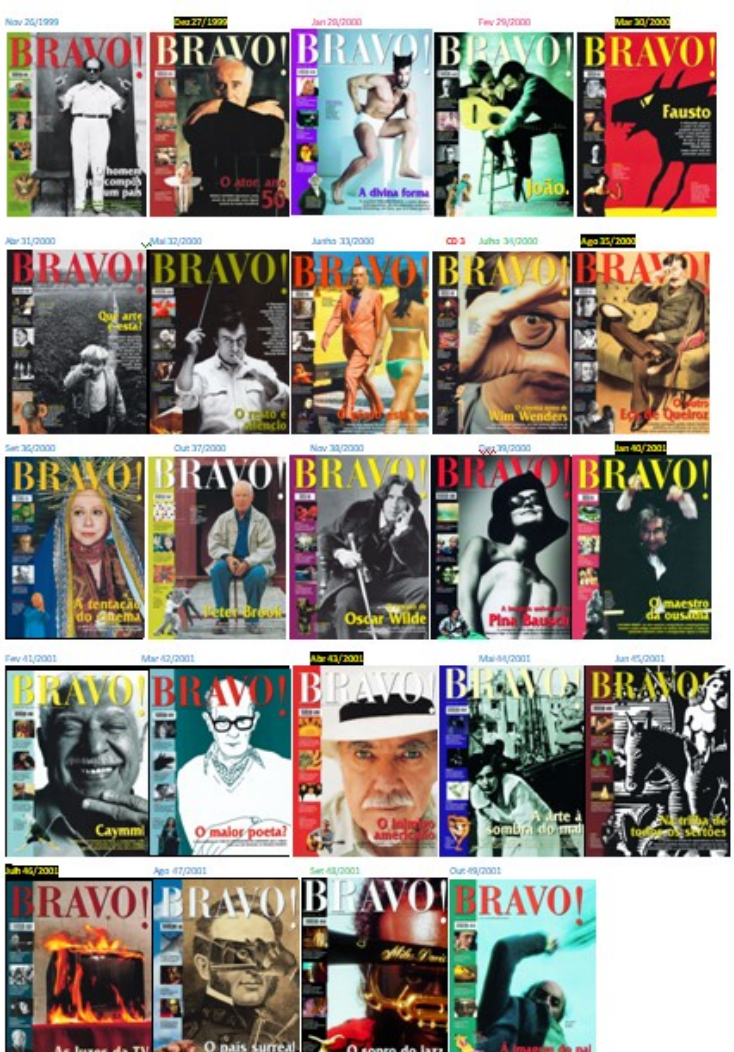

Figura 1 - Capas da revista Bravo! (amostra: 1/1997 - 49/2001).

Fonte: revista Bravo!.

Com o arquivo de imagens foi possível perceber os elementos visuais relacionados ao design e as suas alterações ao longo do tempo de publicação, e também, questões que dizem respeito à relação entre imagem e texto.

Outro olhar foi dado a partir da imersão em um novo processo de catalogação, mais detalhado, com a utilização do programa $B$ ookDB ${ }^{2}$, um software livre utilizado para a catalogação de livros por bibliotecários. Com essa finalidade, algumas adaptações se fizeram necessárias. A figura 2, a seguir, indica quais são os ícones a serem catalogados no programa citado.

\footnotetext{
${ }^{2}$ Referência encontrada na tese intitulada $A$ revista "O Pequeno Luterano" e a formação educativa religiosa luterana no contexto pomerano em Pelotas - RS (1931-1966), de Patrícia Weiduschadt (2012).
} 
RELACult - Revista Latino-Americana de Estudos em Cultura e Sociedade

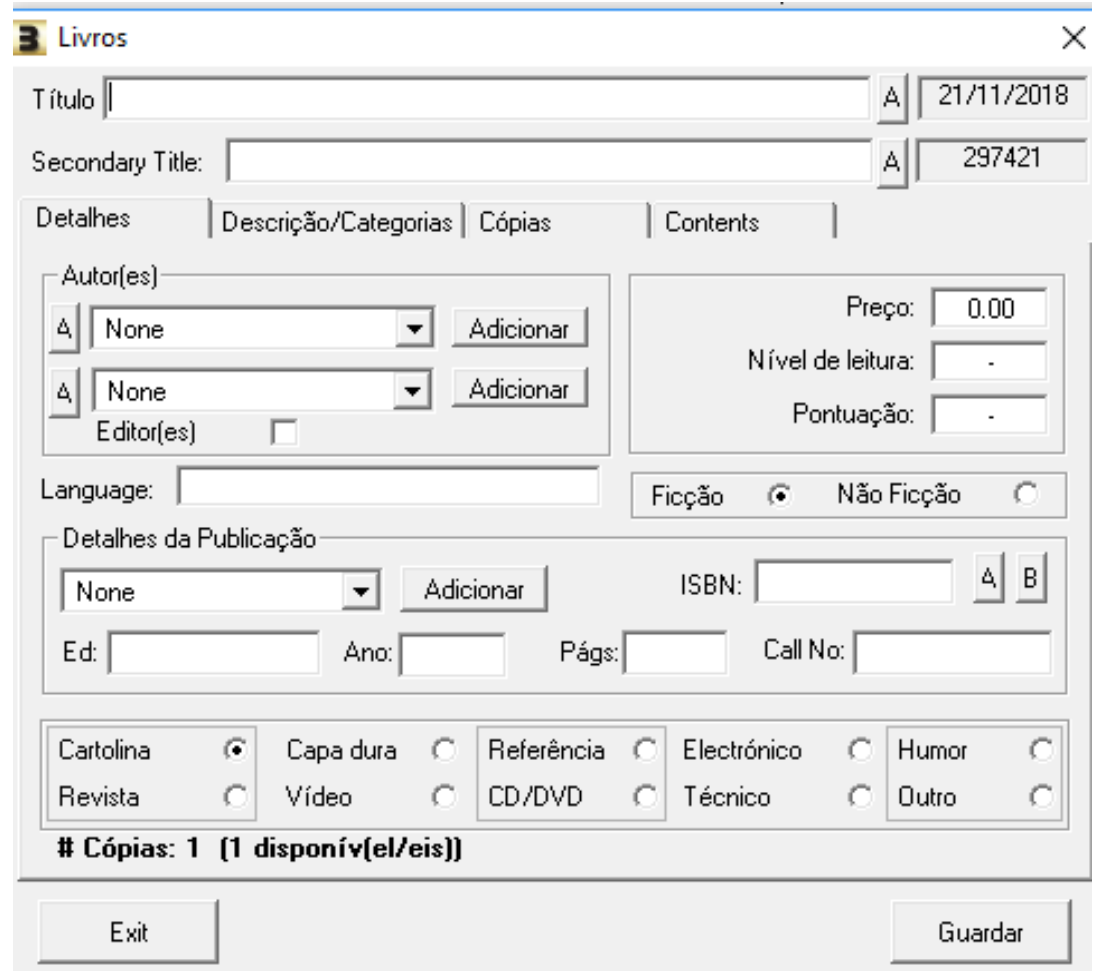

Figura 2 - Caixa do banco de dados BookDB. Fonte: programa BooKDB.

A catalogação no programa BookDB possibilitou que se visualizasse o corpus da revista. A partir do manuseio das fontes para o processo de catalogação no programa citado foi possível conhecer as fontes, a editoria "Artes Plásticas/Artes Visuais", a quantidade de reportagens da editoria referida, o tema abordado nas reportagens, as palavras-chave ou unidades de sentido, as seções extras da editoria, os colaboradores, o contexto sócio-histórico das artes (artistas, recorte temporal na História da Arte) e aspectos que remetem à materialidade da revista como o projeto gráfico e a relação entre fontes textuais e fontes iconográficas.

A criação e a organização dos quadros 1 e 2 , bem como a construção do arquivo de imagens (Figura 1) e do banco de dados no programa BookDB (Figura 2) caracterizam a primeira etapa do percurso teórico-metodológico da pesquisa sobre a revista Bravo!, etapa esta sugerida por Luca (2005). Os passos seguintes dependerão do cruzamento e da análise de dados. Nesse momento, é possível perceber a importância da participação e inserção dos leitores em espaços que educam, tais como museus, galerias de arte e centros culturais. Será, portanto, necessário focar em estudos considerando a categoria "exposição", o que implica em refletir sobre educação. 


\section{Referências}

BASTOS, M. H. C. Espelho de papel: a imprensa e a história da educação. In: ARAÚJO, J. C. de S.; GATTI JÚNIOR, D. (Org.). Novos temas em história da educação brasileira: instituições escolares e educação na imprensa. Campinas: Autores Associados, 2002. p. 151174.

BARROS, José D’Assunção Barros. O campo da História: Especialidades e Abordagens. Petropólis, RJ: Vozes, 2013. p. 222.

BURKE, Peter. O que é História Cultural? RJ: Zahar, 2008. p. 215.

CAPELATO, Maria Helena Rolim. A imprensa na história do Brasil. São Paulo: Contexto EDUSP, 1988. p. 78.

CATANI, D. B.; BASTOS, M. H. C. Educação em Revista: a imprensa periódica e a história da educação. São Paulo: Escrituras Editora, 2002. p. 192.

CHARTIER, R. A História Cultural: entre práticas e representações. 2. ed. Lisboa: Difel, 1987. p. 244.

CRUZ, H. de F.; PEIXOTO, M. do R. da C. Na oficina do historiador: conversas sobre história e imprensa. Projeto História, São Paulo, n.35, p. 253-270, dez. 2007. ISSN: 21762767. Disponível em: https://revistas.pucsp.br/index.php/revph/article/viewFile/2221/1322. Acesso em: 14 ago. 2018.

GALVÃO, A. M. de O.; LOPES, E. M. T. Território Plural: a pesquisa em História da Educação. São Paulo: Ática, 2010. p. 112.

LE GOFF, J.; NORA, P. História: novas abordagens. Rio de Janeiro: Francisco Alves, 1976. p. 196.

232.

História: novos objetos. Rio de Janeiro: Francisco Alves, 1995. p.

193.

. História: novos problemas. Rio de Janeiro: Francisco Alves, 1995. p.

LUCA, T. R. de. História dos, nos e por meio dos periódicos. In: PINSKY, C. B. (Org.). Fontes Históricas. São Paulo: Contexto, 2005. p. 111-153.

MARTINS, A.; LUCA, T. R. de. (Org). História da imprensa no Brasil. 2 ed. São Paulo: Contexto, 2013. p. 303.

NÓVOA, A. A imprensa de educação e ensino: concepção e organização do repertório português. In: BASTOS, M. H. C.; CATANI, D. B. (Org.). Educação em revista. A imprensa periódica e a história da educação. São Paulo: Escrituras, 1997. p. 35-47. 
SCHELBAUER, A. R.; ARAÚJO, J. C. S. História da Educação pela Imprensa. Campinas, SP: Editora Alínea, 2007. p. 274.

VILELA, M. C.; SILVA, C. P. B. da; PINHEIRO, A. R.; BARREIRA, L. C. Estudo de periódicos: possibilidades para a história da educação brasileira. In: MENEZES, M. C. (Org.). Educação, memória, história: possibilidades, leituras. Campinas, SP: Mercado de Letras, 2004. p. 401-450. 